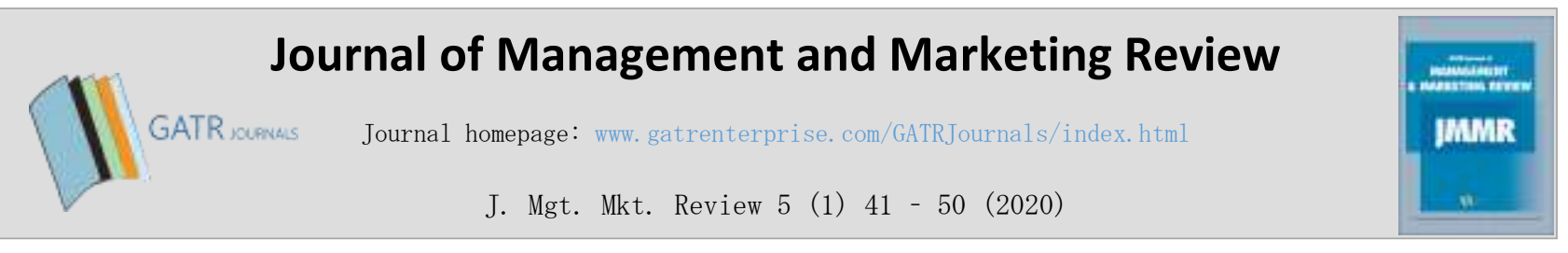

\title{
The Impact of Career Adaptability to the Job Search Strategies of Graduate Students in NCR
}

\author{
Idda Felice S. Francisco ${ }^{1 *}$, Mary Caroline N. Castano ${ }^{2}$ \\ ${ }^{1}$ The Graduate School, University of Sto. Tomas, España Boulevard, Sampaloc,1008, Manila, Philippines \\ ${ }^{2}$ The Graduate School, University of Sto. Tomas, España Boulevard, Sampaloc,1008, Manila, Philippines
}

\begin{abstract}
Objective - Job search is a continuous and developing process which is considered to be an essential part of the worklife of people due to its frequency and extensiveness. Previous literature on job search focusses on how hard job seekers search for a job but only have vague knowledge about the strategies that they use during the search. This study aims to identify the influence of career adaptability on employed graduate students in predicting their direct behaviors in the form of job search strategies used in the job search process. The study also aims to examine the impact of the job search strategies on the number of jobs offers received.

Methodology/Technique -With a total of 388 samples, PLS-SEM is used to examine the relationship of the variables. Findings - Consistent with previous literature wherein job seekers primarily employ focused strategy when they have a career plan in mind, the results reveal that concern is positively and significantly related to focused strategy, as well as curiosity. Further analysis of the data reveals that exploratory strategy is positively and significantly affected by curiosity and confidence.

Novelty - This implies that the more curious and confident graduate students are, the more exploratory they search. Furthermore, the results are consistent with previous studies wherein haphazard strategy was associated with fewer job offers while focused strategy was proven to have a positive effect on the number of job offers.
\end{abstract}

Type of Paper: Empirical.

Keywords: Job Search; Career Adaptability; Graduate Students; Job Search Strategies; Employment.

Reference to this paper should be made as follows: Francisco, I.F.S; Castano, M.C.N. (2020). The Impact of Career Adaptability to the Job Search Strategies of Graduate Students in NCR, J. Mgt. Mkt. Review, 5(1) $41-50$ https://doi.org/10.35609/jmmr.2020.5.1(4)

JEL Classification: A23, A29.

\section{Introduction}

Job search is a continuous and developing process characterized by various changes that require job seekers to make necessary adjustments (Lopez -Kidwell, Grosser, Dineen \& Borgatti, 2013). It is now considered to be an essential part of the work-life of people due to its frequency and extensiveness.

\footnotetext{
* Paper Info: Revised: January 11, 2020

Accepted: March 30, 2020

* Corresponding author: Idda Felice S. Francisco

E-mail: iddaf.francisco@gmail.com

Affiliation: The Graduate School, University of Sto. Tomas Mary Caroline N. Castaño, Manila, Philippines.
} 
According to the report of the U.S. Bureau of Labor Statistics (2019), between the ages of 18-52, individuals held an average of 12.3 jobs. In the Philippines, the Labor Market Updates by the Bureau of Local Employment reveal that the number of job seekers registered from 2015-2018 had continuously increased and the highest increase was from 2017-2018 with a 146\% rise. This implies that more individuals have been searching for employment in the last few years. Moreover, according to the 2018 Labor Turnover Statistics Report (Philippine Statistics Authority, 2019), termination initiated by employees (job quitters) were primarily the main reason for employment loss in 2018. Specifically, 40 to $60 \%$ separated workers were due to voluntary separations or resignations. Furthermore, the report shows that the primary reason why employees quit their job is because they have attained a new job. This report was based on a Labor Turnover Survey conducted by the Philippine Statistics Authority quarterly which aims to capture "job creations" and "job displacements" in business establishments in the Philippines.

Previous job search literature focusses on how difficult it is for unemployed people to look for jobs, but only display a vague knowledge about the strategies that job seekers used in the process (Koen, Klehe, Van Vianen, Zikic, Nauta, 2010). There are different job search strategies that have been identified in previous studies, the most common of which are exploratory, focused, and haphazard strategies (Koen et. al., 2010; Koen, Van Vianen, Van Hooft, Klehe, 2016) which have not received much attention from researchers in the Philippines. Given the different strategies, the study suggests that graduate students will use strategies when looking for a job, however, the degree to which an individual uses these strategies will depend on their career adaptability, which is the readiness to cope with and handle the changes at work and working conditions (Savickas \& Portfeli, 2012). According to Rossier (2015), career adaptability supports an individual's ability to tolerate and handle uncertainties and to cope with educational and career-future fears (Ginevra, Magnano, Lodi, Annovazzi, Camussi, Patrizi, Nota, 2018). Career adaptability is characterized by 4 underlying resources (4Cs) which include concern, control, curiosity, and confidence (Savickas \& Portfeli, 2012).

Despite the extensive literature concerning job search and job search strategies internationally over the last decade, there had been a lack of research conducted in the Philippines. Moreover, there is only 1 study relating to the aforementioned strategies to career adaptability (Koen et. al., 2010). Given that the findings of that study have proven that career adaptability is a significant predictor and definitely influences how job seekers select their job search strategies, the researcher thought of making a study based on this, but this time, in the context of the Philippines. According to Tolentino, Garcia, Restubog, Bordia and Tang (2013), career adaptability is a significant construct as it facilitates the handling and proactive search for improvement which is imperative in the Philippine context. Moreover, it allows individuals to improve their career through job searches (Klehe, Zikic, van Vianen, Koen, \& Buyken, 2012). The majority of existing literature about job searches and career adaptability focusses on undergraduate students and unemployed individuals without much focus on the point of view of graduate school students. Apart from this, most of the studies were conducted in other countries such as the US, Netherlands, China, Canada, Belgium, Romania, Malaysia, Poland, Italy, Portugal, France, Australia, Malaysia; no studies have been conducted in the Phillipines. This study aims to fill this gap by examining the influence of career adaptability to job search strategies that graduate students employ during the process of job searching. This study also aims to examine the effect of the job search strategies on the number of job offers received.

This study contributes to the existing literature about job search strategies, employment, and career adaptability pertaining to graduate students' perspective in the Philippines. The results of this study may also serve as a useful reference for discussions and for future research in business fields such as Human Resource Management, Strategic Management, and General Management. This could also be a catalyst for a course on career planning for graduate students. 


\section{Literature Review}

It has been proven that graduate education is perceived to be significant and beneficial to career and personal development. According to Lin (2011), employment prospects affect the aim for higher education and a Master's degree is expected to be beneficial to the future occupational status and salaries of graduates. Mihail and Kloutsiniotis (2014) argue that a Master in Business Administration (MBA) enhances graduates' career prospects despite any economic situations. Moreover, an MBA helps graduates find better jobs with increasing compensation overtime. It is considered as a formal management education for individuals who seek to advance their career, to increase confidence in work competencies, and for personal development and having this degree also means having a ticket for better job opportunities, higher income, and managerial positions (Ghanie, Adham \& Isa, 2018).

In the Philippines, a $37 \%$ increase in the total number of enrolled graduate students to the Autonomous Higher Education Institutions from 28,281 in 2014/2015 to 44,829 in 2018/2019 suggests that more Filipinos nowadays believe that through graduate education, they can develop their skills and work competencies, have better career opportunities, can be of high value to their current and future employers. The increasing number of individuals taking up graduate education in the Philippines, as well as the lack of research about career adaptability and job search from the graduate students' perspective are two of the reasons why the researcher decided to conduct this study with graduate students as the respondents.

Career Construction Theory conceptualizes human development as driven by adaptation to the social environment with the goal of person-environment integration (Savickas \& Portfeli, 2012). This theory is modeled in 4 parts which include adaptation, adapting, adaptivity, and adaptability. This theory views "willing and able" as "adaptivity and adaptability" or as "readiness and resources" and career adaptability was considered as the career resources. According to this theory, career adaptability is a psychosocial construct that indicates the resources of an individual for handling existing and expected transitions, tasks, and traumas at work. The resources of career adaptability are the self-regulated capacities and strengths of an individual to aid in facing and solving complex and new work-related problems that might arise in the vocational tasks, work transitions, and traumas (Rossier, 2015; Savickas \& Portfeli, 2012). These resources are the 4Cs namely, concern, control, curiosity, and confidence (Savickas \& Portfeli, 2012). The concern is the ability of an individual to plan for future career tasks, changes, and challenges and be positively projected towards it. Control, on the other hand, refers to self-discipline, effort, and persistence that empower individuals to be responsible for their own development in life and career. Curiosity is the exploration of social and career opportunities and future selves and how to react to alternative situations and scenarios. Lastly, confidence reflects self-efficacy in overcoming career obstacles and believing in one's self that their goals can be achieved despite difficulties (Savickas \& Portfeli, 2012).

Career adaptability has garnered significant attention from researchers over the last decade. Previous literatures considered career adaptability as a relevant predictor in the motivation, satisfaction, and persistence, and was also linked to different factors like work experience, parental behaviour, educational environment, traits, work transition, and job search strategies. According to the study of Fang, Zhang, Mei, Chai, and Fan (2018), career adaptability has a mediating effect on the relationship of career motivation, educational environment and optimism. The study of Guan, Deng, Sun, Wang, Cai, Ye, Fu, Wang, Zhang and $\mathrm{Li} \mathrm{(2013)} \mathrm{concludes} \mathrm{that} \mathrm{job} \mathrm{search} \mathrm{self-efficacy} \mathrm{is} \mathrm{a} \mathrm{significant} \mathrm{mediator} \mathrm{in} \mathrm{the} \mathrm{relationship} \mathrm{of} \mathrm{job} \mathrm{search}$ outcomes and career adaptability and among the 4Cs of career adaptability, concern, and control were found to be the strongest predictors of job search self-efficacy.

The job search has been a common research topic that had received significant amount of research attention among several authors. The 2 most common variables in the job search literature are job search selfefficacy and job search behavior. Job search self-efficacy refers to the belief that an individual is capable of attaining the goals and objectives of the firm. On the other hand, the most common job search behavior in job search literature is intensity, which is the effort that job seekers exert during the search (Fort, et. al., 2011). The relationship of these 2 variables had been examined in a number of scholarly journals (Lin \& Flores, 
2013; Fort, et. al., 2011; Bao \& Luo, 2015; Saks, Zikic \& Koen, 2015; Yizhong, Lin, Baranchenko, Lau, Yukhanaev \& Lu, 2017; Taggar \& Kuron, 2016) and results have shown a significant relationship between them.

Different types of job search strategies have been identified by different authors in past literature. There are formal job search, informal job search, digital job search, and institutionalized job search (Pirog, 2016); formal job search strategy, informal job search strategy, and joint channels (Xiong et. al., 2017). However, this study focusses on exploratory strategy, focused strategy, and haphazard strategy (Koen et. al., 2010; Koen, et. al., 2016). An exploratory strategy suggests that job seekers are committed and are motivated in the job search to fully explore all possible options. A focused strategy, on the other hand, implies that individual job seekers have clear career and employment goals and persevere in the job search until they identify their top choices. Finally, a haphazard strategy is a trial and error approach having vague employment/career goals and objectives (Koen et al 2010; Koen et al, 2016). Based on the definitions, it simply implies that the haphazard strategy intends to find any type of job, whereas exploratory and focused job search strategies both aimed at finding a satisfying and matching job. At the same time, focused strategy is more goal-oriented than exploratory and haphazard job search strategies (Koen et. al., 2010). However, according to Koen et. al. (2016), job seekers employing focused strategy may either be pursuing clearer employment goals or may be limiting themselves to lesser career options so as not to exert much effort. Hence, this may rather reflect lowquality than high-quality search behaviour at the start of the job search and may not improve the chance of finding employment. In the study of Taggar and Kuron (2016), the positive association of job search selfefficacy to the use of exploratory and focused strategies and the negative association with haphazard strategy have been confirmed. In addition, exploratory and focused strategies were found to be related to higher quality job search behaviour, while haphazard strategy is related to poor decision-making and lesser applications. Despite numerous studies globally, these strategies have not received much attention from researchers in the Philippines, although other international studies have proven their impact on the job search process especially its effects on the job search outcomes. Studies determining the factors that make individuals rely on a specific strategy have also not received much attention over the years.

Consistent with previous studies, this study also uses the theory of planned behavior (TPB). TPB has been widely used in the job search literature and is considered to be a strong model for the job search mechanisms (Yizhong et. al., 2017). According to Ajzen (1991), which was cited in Zikic and Saks (2009), TPB suggests that the main predictor of the behavior in question is the individual's intention to engage in a behavior, and the intention to engage in a certain behavior is a function of one's attitude toward the behavior, subjective norm, and perceived behavioral control which is similar to perceived self-efficacy. This theory explains that the intention to complete the actions is the best predictor of behavior (Yizhong et. al., 2017). In this study, the job search intention is the number of job offers which serves as the immediate predictor of the job search strategies used, whereas the subjective norms, attitude towards the actions, and perceived behavioral control are the underlying resources of career adaptability (4Cs) or the predictors of the intention.

Based on the definitions of the variables in the study, which are the 4Cs of career adaptability and the job search strategies, the study proposed to test the following hypotheses:

(Ha1) Career control (a) relates positively to focused strategy and (b) relates negatively to haphazard strategy.

(Ha2) Career concern (a) relates positively to focused strategy and (b)relates negatively to haphazard strategy.

(Ha3) Career curiosity (a) relates positively to exploratory strategy and (b)relates negatively to focused strategy. 
(Ha4) Career confidence relates positively to exploratory strategy; and

(Ha5) The use of exploratory job search strategy (a) relates positively to the number of job offers, while the use of focused and haphazard job search strategies (b) relates negatively to the number of job offers.

To further understand the hypothesis and the direct associations of the variables, see Figure 1 for the conceptual framework.

\section{Research Methodology}

\subsection{Participants of the Study}

The researcher was able to get the list of the Autonomous Higher Education Institutions from the official website of the Commission on Higher Education (CHED), CMO No. 58, series 2017. Upon acquiring the list, the researcher emailed the Data Department of CHED to request for the total number of the enrolled graduate students in these institutions. Based from the list, the researcher selected the schools using a purposive technique with the following criteria:

the school must be registered as an Autonomous Higher Education Institution;

must have more than 500 enrolled graduate students; and

must be located in the National Capital Region. Eight Higher Education Institutions met the criteria.

A total of 450 survey questionnaires were distributed to the graduate students of the selected educational institutions and 388 of these were accepted and utilized in the study. Of the 388 respondents, almost half are aged 25-29 years old yielding 41\%. A large number of the respondents are taking up Master's Degree yielding $97 \%$ and have been employed with their current job for 4 to 6 years (34\%). The majority of the respondents are also female with $56 \%$.

\subsection{Research Instruments}

The survey questionnaire used in the study consists of 3 parts. The first part includes the sociodemographic profile of the participants, as well as the number of job offers received by respondents. Demographic items are included for the purpose of knowing the basic information of the participants. The second part is the Career Adapt-Abilities Scale (CAAS), used to measure the career adaptability of the respondents. This is a 24-item scale which is equally divided into four subscales that measure career adaptability's underlying resources (Tolentino, Garcia, Restubog, Bordia \& Tang, 2013). Items were measured using a 4-point Likert scale with anchors from (1) not strong to (4) strongest. The last part is a 16item measure of Crossley and Highhouse (2005), which was used in Koen et. al. (2010) to measure the job search strategies of the respondents. The 16-item scale measured the degree to which respondents engaged in the different job search strategies. The response was also made on a 4-point Likert scale ranging from (1) strongly disagree to (4) strongly agree.

\subsection{Data Gathering Procedure}

To determine the reliability of the survey questionnaire, the researcher conducted a pre-test with 30 respondents. The result of the pre-test using Cronbach Alpha showed that all items are reliable with high internal consistency having 0.839 alpha coefficients. This posits that the survey questionnaire is of good reliability. The survey was conducted through personal distributions of questionnaires to the respondents for all the selected higher education institutions except for Ateneo De Manila University. As advised by the 
university's representative, an online form of the survey questionnaire was created. The link of the online form was then distributed through an email blast to the graduate students of the educational institution.

\subsection{Partial Least Square-Structural Equation Model (PLS-SEM)}

The study used primary data from the survey questionnaires and these were analyzed using descriptive statistics. Partial Least Square-Structural Equation Model (PLS-SEM) was employed to interpret the relationships between the variables.

Descriptive statistics were used to summarize the information as well as to assess and describe the data collated. Furthermore, it was used to examine the frequency and percentage distributions of the respondents' demographic profile. Given that the variables in this study are latent and unobserved, testing the relationships and dependences between and among them can be addressed by Partial Least Square-Structural Equation Model (PLS-SEM). This tool is component-based and requires assumptions that are less rigorous and strict in relation to the measurement levels of the apparent variables, normality of two or more variable quantities, and sample size. (Dimaunahan \& Amora, 2016). In line with this, PLS-SEM was used to investigate the relationship between the variables and in testing the hypotheses.

\subsection{Tables}

Table 1. Parameter Estimates of the Structural Model

\begin{tabular}{|c|c|c|c|c|}
\hline & Path Coefficients $(\beta)$ & SE & p-value & f2 \\
\hline Control $\rightarrow$ Haphazard Strategy & -0.069 & 0.050 & 0.086 & 0.004 \\
\hline Control $\rightarrow$ Focused Strategy & -0.004 & 0.051 & 0.466 & 0.001 \\
\hline Concern $\rightarrow$ Haphazard Strategy & 0.080 & 0.050 & 0.056 & 0.006 \\
\hline Concern $\rightarrow$ Focused Strategy & 0.195 & 0.049 & 0.000 & 0.062 \\
\hline Curiosity $\rightarrow$ Exploratory Strategy & 0.290 & 0.049 & 0.000 & 0.100 \\
\hline Curiosity $\rightarrow$ Focused Strategy & 0.250 & 0.049 & 0.000 & 0.087 \\
\hline Confidence $\rightarrow$ Exploratory Strategy & 0.103 & 0.050 & 0.020 & 0.026 \\
\hline Haphazard Strategy $\rightarrow$ Number of Jobs & -0.093 & 0.050 & 0.003 & 0.010 \\
\hline Exploratory Strategy $\rightarrow$ Number of Jobs & 0.067 & 0.050 & 0.091 & 0.002 \\
\hline Focused Strategy $\rightarrow$ Number of Jobs & 0.116 & 0.050 & 0.010 & 0.013 \\
\hline
\end{tabular}

\subsection{Illustrations}

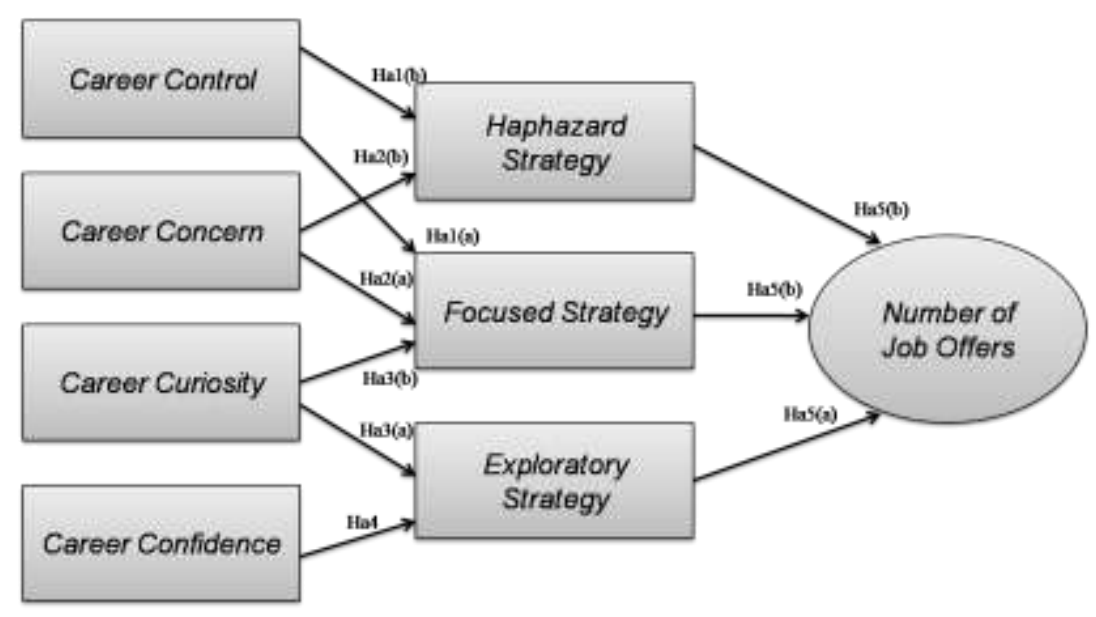


Figure 1. Conceptual Framework

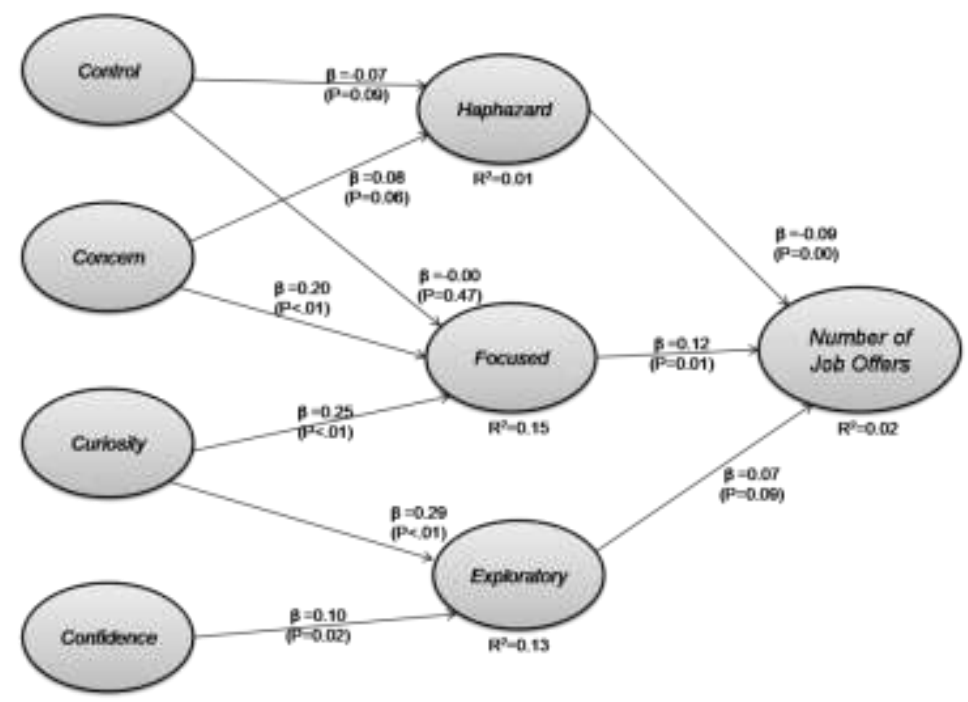

Figure 2. Hypothesized Model Test Results

\section{Results and Discussion}

To test the hypotheses, PLS-SEM was employed. Table 1 shows the results of the structural model while Figure 2 summarizes the results of the research model of the study. Table 1 shows that career control has no significant effect to focused $(\beta=-0.004, p=0.466, f 2=0.001)$ and haphazard strategy $(\beta=-0.069, p=0.086$, $\mathrm{f} 2=0.004)$, hence, Hal is rejected. Moreover, career concern $(\beta=0.195, \mathrm{p}=0.000, \mathrm{f} 2=0.062)$ and career curiosity $(\beta=0.250, \mathrm{p}=0.000, \mathrm{f} 2=0.087)$ displayed significant positive effect to focused strategy supporting $\mathrm{Ha} 2$ (a) and rejecting $\mathrm{Ha} 3(\mathrm{~b})$ which was initially predicted to have a negative effect. Career curiosity $(\beta=0.290, p=0.000, f 2=0.100)$ and career confidence $(\beta=0.103, p=0.20, f 2=0.026)$, both showed significant positive effect to exploratory strategy supporting Ha3(a) and Ha4. The positive path coefficients indicate that the higher level of career concern and career curiosity would lead to a greater focused strategy and that a higher level of career curiosity and career confidence would also lead to higher level of exploratory strategy. However, career concern $(\beta=0.080, \mathrm{p}=0.056, \mathrm{f} 2=0.006)$ revealed to have no significant effects on haphazard strategy. On the other hand, if the path coefficients are negative, it means that the higher level of the independent variable would lead to a lower level of the dependent variable.

Regarding the last hypothesis, further analysis of data revealed that exploratory strategy $(\beta=0.067$, $\mathrm{p}=0.091, \mathrm{f} 2=0.002)$ has no significant effect to the number of job offers, while haphazard $(\beta=-0.093, \mathrm{p}<0.05$, $\mathrm{f} 2=0.010)$ reveals to have a significant negative effect to the number of job offers. Furthermore, the focused strategy $(\beta=0.116, p=0.010, f 2=0.013)$ revealed to have a significant positive effect on the number of job offers. This indicates that the higher the use of focused strategy, the higher the number of job offers.

\subsection{Recommendations and Directions for Future Research}

Career adaptability has been confirmed to be a good predictor of job search strategies with concern, curiosity, and confidence proven to have a significant effect on focused and exploratory strategies. In line with this, the labor and employment organizations can conduct training programs and seminars to job seekers about career adaptability. Moreover, since career adaptability provides self-regulated resources for careerrelated activities of the job seekers, higher education institutions can add career courses that intend to improve individuals' career adaptability which will benefit the career development of the graduate students in the long run. The results of the last hypothesis test suggests that career counselors and educators should also pay attention to other job search strategies and methods such as informal job search strategy, formal job 
search strategy, digital job search, and institutionalized job search that may improve job seekers' employability. The use of these strategies and methods can eventually increase their chances of employment.

The limitations of this study provide an avenue for further research. First, the respondents of the study are the graduate student. In general, future studies can integrate the different programs that the graduate students are currently taking up and see if there will be different results. Second, the job search strategies that were utilized in the study are limited to three strategies namely exploratory, focused, and haphazard strategies and the results showed that only focused strategy has a significant positive to the number of job offers. Future researchers can utilize other job search methods and strategies like formal job search, informal job search, digital job search, and institutionalized job search and joint channels (Pirog, 2016; Xiong, Li, Westlund, Pu, 2017) to give job seekers broader choices on how to strategize during the job search. Lastly, since the current study was only limited to the number of jobs offers received, future researchers can investigate the quality of the job obtained after 6-8 months upon employment (Koen et. al., 2010). In line with this, a qualitative approach can also be integrated for more validated and verified results.

\section{Conclusion}

This study has investigated the impact of career adaptability underlying resources (concern, control, curiosity, and confidence) on the job search strategies of graduate students in the National Capital Region. The influence of the job search strategies on the number of job offers was examined as well. Given that concern is the ability to plan for the future with clear employment goals and control refers to the effort, persistence, and self-discipline of the job seekers, these should encourage the use of focused strategy and not haphazard strategy. The results of the study revealed that control has no significant effect on both focused and haphazard strategy, whereas concern has shown significant positive effect on focused strategy and no significant relationship with haphazard strategy. This is consistent with the study of Koen et. al. (2010) wherein job seekers primarily employ focused strategy when they have clear career plan in mind. On the other hand, since curiosity is the exploration of social opportunities which entails being open to informationseeking behavior (Savickas \& Portfeli, 2012) and is the initiative to learn about the jobs that individual might want to attain (Oncel, 2014) it can be predicted that it will have a significant relationship with exploratory strategy.

Moreover, career confidence is also predicted to be significantly related to exploratory strategy since having a high level of self-efficacy can develop a wider scope of the job search activities. However, given that focused strategy relies on the limited focus of their top work choices, high curiosity can likely lessen the use of this strategy. In the present study, career curiosity revealed to have significant positive effect on both exploratory and focused strategy. Further, the findings revealed that graduate students primarily employ exploratory strategy when they are curious to search for possible career opportunities and that the exploration of possible opportunities can positively affect the behavior of graduate students in having clear employment goals which lead them in employing focused strategy as well. Similar to career curiosity, career confidence also revealed to have significant positive effect on exploratory strategy.

The results further show that exploratory has no significant relationship to the number of job offers, in contrast from previous studies (Koen et. al., 2010 \& Koen et. al., 2016), wherein exploratory strategy had been significantly and positively related to the number of job offers. Focused strategy and haphazard strategy, on the other hand, showed a significant relationship to the number of job offers, with a focused strategy having a positive effect while haphazard strategy showed a negative effect. This result is consistent with previous studies (Koen et. al., 2010; Koen et. al., 2016) wherein haphazard strategy was associated with fewer job offers while focused strategy was proven to have positive effect on the number of job offers.

In conclusion, the present study showed that among the 4Cs of career adaptability, concern, and curiosity have a significant positive effect on focused strategy. In addition, the more curious and confident graduate students are, the more exploratory they search. Moreover, among the strategies, findings revealed that focused strategy leads to a higher number of job offers compared to the haphazard strategy which leads to 
fewer job offers. Consistent with previous studies (Koen et. al., 2010; Guan et. al., 2013), this study has shown significant evidence about career adaptability as a valid predictor of job search strategies, and that only focused strategy can lead to a higher number of job offers.

\section{References}

Bao, Z., \& Luo, P. (2015). How college students' job search self-efficacy and clarity affect job search activities. Social Behavior and Personality: an international journal, 43(1), 39-51.https://doi.org/10.2224/sbp.2015.43.1.39

Dimaunahan, D. V., \& Amora, J. T. (2016). An investigation of organizational creativity of Micro, Small and MediumScale Restaurants in the Philippines using Structural Equation Modeling. GSTF Journal on Business Review (GBR), 4(3). https://10.5176/2010-4804_4.3.384

Fang, W., Zhang, Y., Mei, J., Chai, X., \& Fan, X. (2018). Relationships between optimism, educational environment, career adaptability and career motivation in nursing undergraduates: A cross-sectional study. Nurse education today, 68, 33-39. https://doi.org/10.1016/j.nedt.2018.05.025.

Fort, I., Jacquet, F., \& Leroy, N. (2011). Self-efficacy, goals, and job search behaviors. Career Development International. http://dx.doi.org/10.1108/13620431111168886.

Ginevra, M. C., Magnano, P., Lodi, E., Annovazzi, C., Camussi, E., Patrizi, P., \& Nota, L. (2018). The role of career adaptability and courage on life satisfaction in adolescence. Journal of adolescence, 62, 1-8. https://doi.org/10.1016/j.adolescence.2017.11.002.

Guan, Y., Deng, H., Sun, J., Wang, Y., Cai, Z., Ye, L., ... \& Li, Y. (2013). Career adaptability, job search self-efficacy and outcomes: A three-wave investigation among Chinese university graduates. Journal of Vocational Behavior, 83(3), 561-570. https://doi.org/10.1016/j.jvb.2013.09.003

Klehe, U. C., Zikic, J., van Vianen, A. E., Koen, J., \& Buyken, M. (2012). Coping proactively with economic stress: Career adaptability in the face of job insecurity, job loss, unemployment, and underemployment. The role of the economic crisis on occupational stress and wellbeing, 10, 131-176. https://doi.org/10.1108/S14793555(2012)0000010008

Koen, J., Klehe, U. C., Van Vianen, A. E., Zikic, J., \& Nauta, A. (2010). Job-search strategies and reemployment quality: The impact of career adaptability. Journal of Vocational Behavior, 77(1), 126-139. http://doi.org/10.1016/j.jvb.2010.02.004.

Koen, J., van Vianen, A. E., van Hooft, E. A., \& Klehe, U. C. (2016). How experienced autonomy can improve job seekers' motivation, job search, and chance of finding reemployment. Journal of Vocational Behavior, 95, 31-44. http://dx.doi.org/10.1016/j.jvb.2016.07.003.

Lin, M. J. (2011). Women's aspirations for graduate education in Taiwan. International Journal of Educational Development, 31(5), 515-523. https://doi.org/10.1016/j.ijedudev.2010.12.005

Lin, Y. J., \& Flores, L. Y. (2013). Job search self-efficacy of East Asian international graduate students. Journal of Career Development, 40(3), 186-202. https://doi.org/10.1177/0894845311418655

Lopez-Kidwell, V., Grosser, T. J., Dineen, B. R., \& Borgatti, S. P. (2013). What matters when: A multistage model and empirical examination of job search effort. Academy of Management Journal, 56(6), 1655-1678. https://doi.org/10.5465/amj.2011.05468

Mihail, D. M., \& Kloutsiniotis, P. V. (2014). The impact of an MBA on managerial skills and career advancement: The Greek case. The International Journal of Management Education, 12(3), 212-222. https://doi.org/10.1016/j.ijme.2014.04.002

Ghanie, S. K. M., Adham, K. A., \& Isa, R. M. (2018). Organizational Socialization Process of MBA Graduates. Jurnal Pengurusan (UKM Journal of Management), 52. http://ejournals.ukm.my/pengurusan/article/view/26172

Öncel, L. (2014). Career adapt-abilities scale: Convergent validity of subscale scores. Journal of Vocational Behavior, 85(1), 13-17. https://doi.org/10.1016/j.jvb.2014.03.006

Piróg, D. (2016). Job search strategies of recent university graduates in Poland: plans and effectiveness. Higher Education, 71(4), 557-573. https://doi.org/10.1007/s10734-015-9923-5

Rossier, J. (2015). Career adaptability and life designing. https://psycnet.apa.org/record/2015-15337-011

Saks, A. M., Zikic, J., \& Koen, J. (2015). Job search self-efficacy: Reconceptualizing the construct and its measurement. Journal of Vocational Behavior, 86, 104-114. https://doi.org/10.1016/j.jvb.2014.11.007 
Savickas, M. L., \& Porfeli, E. J. (2012). Career Adapt-Abilities Scale: Construction, reliability, and measurement equivalence across 13 countries. Journal of vocational behavior, 80(3), 661-673. https://doi.org/10.1016/j.jvb.2012.01.011

Taggar, S., \& Kuron, L. K. (2016). The toll of perceived injustice on job search self-efficacy and behavior. Career Development International. https://doi.org/10.1108/CDI-10-2015-0139

Tolentino, L. R., Garcia, P. R. J. M., Restubog, S. L. D., Bordia, P., \& Tang, R. L. (2013). Validation of the Career Adapt-Abilities Scale and an examination of a model of career adaptation in the Philippine context. Journal of Vocational Behavior, 83(3), 410-418. https://doi.org/10.1016/j.jvb.2013.06.013

Xiong, A., Li, H., Westlund, H., \& Pu, Y. (2017). Social networks, job satisfaction and job searching behavior in the Chinese labor market. China Economic Review, 43, 1-15. https://doi.org/10.1016/j.chieco.2017.01.001

Xie, Y., Lin, Z., Baranchenko, Y., Lau, C. K., Yukhanaev, A., \& Lu, H. (2017). Employability and job search behavior: A six-wave longitudinal study of Chinese university graduates. Employee Relations, 39(2), $223-239$. http://dx.doi.org/10.1108/ER-02-2016-0042 